\title{
Aiding Transition to University Through an Outdoor Orientation Program: Accelerated Friendships
}

Luke Pickard, Department of Sport, Health, and Nutrition, Leeds Trinity University

Julie A. Brunton, College of Health, Wellbeing, and Life Sciences, Sheffield Hallam University

James McKenna, Carnegie Faculty, Leeds Beckett University

Andrea Utley, School of Biological Sciences, University of Leeds

Outdoor orientation programs are used to provide experiences which aid transition to university. We investigated how an outdoor orientation program for first-year university students in England, UK accelerates social group development, which in turn aids transition and adaptation to university. We employed mixed methods data collection, including the Student Adaptation to College Questionnaire (SACQ) (Baker \& Siryk, 1989) and semi-structured interviews. The questionnaire indicated that the outdoor orientation program significantly aided adaptation to university. The benefits of accelerated social group formation for transitioning young adults are explored through thematic analysis and explained through psychological theory.

Keywords: university transition, outdoor orientation program, social groups, belonging, friendships 
Transition to university is a significant psychosocial experience that involves change to emerging adults' individual sense of self at a time when the role of identity and social interaction are particularly important (Carr, Colthurst, Coyle, \& Elliott, 2013). During this critical initial period a variety of factors could make this an unpleasant experience that may cause young adults to want to leave their university. Feelings of isolation and not fitting in are primary reasons for leaving (Thomas, 2012). These young adults are less engaged with the university and less engaged with their peers.

It has been proposed that a student's early experiences of the university environment create a "script" that can powerfully shape the way in which that individual interacts with their university, peers, and staff for the remainder of their time in higher education (McDonald \& Gunn, 1997). Therefore, it is important that these early experiences following enrollment provide a physical, psychological, and social environment that challenge the problematic scripts that some young adults may create.

Major change or transition can be a mental health risk factor and greatly effect experiences of psychological wellbeing (Rubin \& Wright, 2015). Many young adults expect to experience difficulties such as isolation, which may result in a negative effect on psychological wellbeing (Carr et al., 2013). One way in which these problems of isolation may be addressed is through higher levels of social integration. Young adults who integrate and engage socially are more likely to achieve good adaptation and transition to university life and an increased chance of persistence (Wolfe \& Kay, 2011).

From the perspective of a university, retention and student satisfaction are important to both its reputation and its finances. Many universities have not yet been able to translate what is known about student satisfaction and retention into forms of action that have led to substantial gains in completion or continuation rates (Tinto, 2006). Early delivery of intervention is key in developing valued, engaged, dedicated, and motivated students, all of which reduce attrition (Schofield \& Dismore, 2010). To aid student transition and integration, universities should be encouraged to pay more attention to the relational side of student development. Many universities pay limited attention to students' social 
integration, instead placing a heavier focus upon academic integration (Peel, 2000; Grayson \& Grayson, 2003). Tackling these important social transitional issues is a potentially underutilized strategy for universities to improve student experience and retention.

\section{Outdoor Orientation Programs}

This research into improving transition and adaptation to university during this potentially difficult period investigates a program which has similarities to the mainly North American phenomenon of wilderness orientation programs and outdoor orientation programs (OOPs). OOPs benefit young adults in a number of ways, including enhancement of relationships with peers and academic staff (Pickard, 2019). They have also been found to aid personal growth (Vlamis, Bell, \& Gass, 2011), resilience (Allan, McKenna, \& Robinson, 2008), wellbeing, and readiness for college (Hill, Posey, Gómez, \& Shapiro, 2018). 00Ps have also been identified as key components in reducing attrition and increasing retention rates at university (Schofield \& Dismore, 2010; Bell \& Chang, 2017). Bell and Chang (2017) carried out a critical review of program impacts on retention and graduate outcomes, comparing differences between a control group, comparison group, and a convenience sample; the researchers found similarities between sampling through random selection and the comparison group, but not for the convenience sampling, with generally positive retention results for participation in OOPs. Small effect sizes were shown for retention (OR $=1.91-2.38$ ) and graduation (OR =1.07-1.81), but these were not significant.

OOPs have been shown to be more effective than other types of orientation programs (Bell, Holmes, \& Williams, 2010). Transition processes are addressed and manipulated in 00Ps by providing a platform for young adults to develop constructive social support systems. This is especially important because many young adults fear failing socially more than failing academically (Vlamis, Bell, \& Gass, 2011). There is evidence that young adults who participate in an OOP develop significantly greater degrees of social support compared to participating in other orientation experiences (Bell, 2005), and that an OOP can help reinforce students' 
sense of belonging (Richmond \& Sibthorp, 2019). These peer relationships can both provide critical emotional support and strengthen educational gains (Bell, Gass, Nafziger, \& Starbuck, 2014).

Much outdoor orientation program research continues to rely on descriptive or anecdotal evidence rather than investigate what elements lead to specific participant development and program outcomes (Sibthorp, Paisley, \& Gookin, 2007). This issue is long-standing given that over three decades ago Ewert (1983) stated the outcomes of this type of program are known but there is no clear explanation of the processes at work which cause the outcomes. The general consensus is that the personal, social, and environmental processes provided by an OOP create positive adaptations (Bell et al., 2014), yet the unexplained complexity in today's evidencebased climate is problematic (Bell et al., 2014). Much of the literature places a focus upon the benefit outcomes rather than how these outcomes are achieved and places an emphasis on theory rather than empirical research (McKenzie, 2000).

It has been concluded that qualitative research such as interviews, questionnaires, and observations are required to examine in-depth data which could inductively discover new program characteristics that may influence outcomes (McKenzie, 2000). Further outcome-based and evidence-based studies are needed to examine the elements of OOPs to better understand how they support student development (Cortez, 2014).

\section{Attachment Theory}

Explaining the possible psychological processes that underpin early university experiences for these emerging adults is important. Attachment theory can be applied to this transitional period. Early attachment experiences form an integral part of the individual's psychological organization, or as Bowlby (1980) termed it, "internal working models." These individual differences may influence the likelihood that individuals will be able to orchestrate experiences in the new environment that allow them to satisfy psychological needs for attachment, which can aid security and comfort. By seeking out positive social relationships and connections early in the university transition process, individuals may be able to 
counteract possible feelings of isolation and loneliness (Maxwell et al., 2013).

\section{Social Penetration Theory}

Altman and Taylor's (1973) social penetration theory describes the stages of friendship. As relationships develop, interactions penetrate deeper and deeper into private and personal matters. This exposes vulnerabilities, so trust has to be developed along the way. Penetration goes through five stages: Orientation, Exploratory Affective, Affective, Stable, and Depenetration. The Orientation stage involves small talk and simple conversations following standards of social desirability and norms of appropriateness with acquaintances. The Exploratory Affective stage is when people begin to reveal themselves, expressing personal attitudes about moderate topics such as government and education. This is the stage of casual friendship. The Affective stage is when people start to talk about private and personal matters. Criticism and arguments may arise and deeper meaningful friendships and beginnings of intimate relationships occur. The Stable stage is where relationships reach a plateau in which personal things are shared and each can predict the emotional reactions of the other person; as best friends or lifelong friends or a long-term intimate relationship. The final stage is the Depenetration stage that is optional because not all relationships and friendships deteriorate. This theory is applicable to an OOP because the design of such programs and activities provides a clear platform to accelerate through the stages of friendship.

\section{Research Questions}

1) To determine whether an OOP can aid adaptation to university for first-year students.

2) To discuss the social processes which occur during an OOP.

3) To explain potential findings using psychological theory. 


\section{Method}

This research took a critical realism stance (Bhaskar, 1975) which holds that quantitative and qualitative research can be used in combination to reduce potential limitations. The critical realism approach has received growing support as the use of mixed methods research has increased in the social sciences (Shannon-Baker, 2015). It was particularly useful within this research project by placing focus upon the context, mechanism, and outcome of an intervention.

We approached the research process using a data-led bottom-up inductive approach. This was chosen to aid in the trustworthiness of the analysis process. Lincoln and Guba (1985) proposed four criteria that can help establish trustworthiness of a qualitative study. These criteria correspond with rigor applied to positivist investigation (Credibility - Internal Validity, Transferability - Generalizability, Dependability Reliability, and Confirmability - Objectivity; Shenton, 2004). We ensured credibility of the investigation by using the well-established research method of thematic analysis. The interview schedules and specific interview questions were not derived from a previous study, they were constructed then checked and altered based on feedback from the research team. The questions were then tested in a pilot interview and subsequently modified or changed where appropriate. Transferability of the findings was attempted by providing enough contextual information to allow the reader to relate the findings in the analysis to their own experience. Transferability was also improved through thick description of the phenomena under investigation. Dependability was aided by detailed description of the procedure and methods employed in analysis, allowing a future researcher to repeat the investigation and allowing the reader to decide if the analysis has been conducted using appropriate methodological practices. Confirmability was achieved by triangulation of thematic findings with the research team. The researchers also drew on past studies and theoretical understanding. 


\section{Thematic Analysis}

The semi-structured interviews were analyzed using thematic analysis, which is a method for systematically identifying, organizing, and offering insight into patterns of meaning or themes across a data set. Thematic analysis is a structured method of identifying commonalities within a data set and of making sense of those commonalities. Patterns can be identified across any data set and combined in a way to make sense across a range of data on a range of issues. The purpose of analysis is to identify those themes relevant to answering a particular research question. This research used Braun and Clarke's (2006) six-phased approach to thematic analysis: 1) Familiarizing yourself with the data: involves immersing yourself in the data by reading and rereading textual data (e.g., transcripts of interviews); 2) Generating initial codes: codes identify and provide a label for a feature of the data; 3) Searching for themes: representing some level of patterned response or meaning within the data set ; 4) Reviewing potential themes: essentially about quality checking; 5) Defining and naming themes: to provide a coherent overall story about the data; and 6) Producing the report (Braun \& Clarke, 2006).

\section{Context for the Current Research}

The university under investigation was a small university of less than 5000 students; it was established in the 1960s in England, UK. The university enrolls a relatively large number (43.9\%) of students from low socio-economic backgrounds. The university's student body identifies as $66.3 \%$ female and $33.7 \%$ male. Of the total enrolled students, $55.3 \%$ are 20 years of age and under, $25.5 \%$ are $21-24$, and $19.2 \%$ are 25 and older and classed as mature students. Full-time students make up $96 \%$ of the student body, with $4 \%$ of students studying on a part-time basis. UK nationals account for $99.3 \%$ of the student body, while $0.2 \%$ of students are EU nationals and $0.5 \%$ are non-EU nationals. Ninety-eight percent of the students studied at state schools for their secondary education, while the remaining $2 \%$ studied at private schools. Undergraduates account for $83 \%$ of the student body, and $17 \%$ are postgraduates (Higher Education Statistics Agency [HESA], 2019a). Figures from 2016-2017 indicated 
89.8\% of UK domiciled full-time undergraduate entrants progressed from Year 1 to Year 2 at this university, noticeably falling below the UK average which currently stands at 93.7\% (HESA, 2019b).

The 00P was selected by the university as a strategy to aid student adaptation. Students from three degree programs were included in the outdoor orientation program. The OOP was a three-day residential experience based in rural England. It was scheduled to run in the first week of teaching for the first-year students' first term. The program was fully funded by the university. The 0OP was being used to maximize its impact in a critical period of the students' higher education experience.

The accommodation was a large hostel. Students took part in a range of activities including team building, gorge scrambling, caving, abseiling, and raft building, with night walks and evenings nominated as free time; the hostel had a bar, a games room, and other social spaces. Students were allocated roommates and activity groups.

\section{Design}

This study used a mixed methods holistic approach. The quantitative analysis was used first to distinguish if there was a difference between students who attended the OOP and a comparison group who did not. The subsequent qualitative analysis was undertaken to try and determine why these differences occurred. The qualitative analysis also sought to provide an overview of possible improvements and solutions that could not be achieved using a single research method. The project comprised of student questionnaires and semi-structured interviews with students.

The questionnaire used was the Student Adaptation to College Questionnaire (SACQ; Baker \& Siryk, 1989). This measures overall student adaptation to university as well as four subscales: social, personal, academic, and institutional attachment. It consists of 63 statements which are scored on a seven point scale. This was distributed to all participants of the outdoor orientation program and a comparison group which did not attend an outdoor orientation program. Credé and Niehorster (2012) conducted a meta-analysis of 237 studies which utilized the SACQ; this incorporated the responses of 44668 students. Results indicated that the 
predictive validity of academic adjustment was almost as strong as grade point average and SAT scores with regard to retention and academic achievement. They also highlighted that institutional attachment has the largest correlation with retention rates. The SACQ is considered to be the most predominantly utilized measure of student adjustment in higher education around the world (Pickard, 2019). The questionnaire demonstrates high internal validity and provides a link between adjustment, retention, and academic attainment (Mattern \& Patterson, 2009). The SACQ is therefore considered a useful tool as part of the proposed mixed methods design of the current study.

Semi-structured interviews were conducted with 14 students who attended the outdoor orientation program and eight students who did not attend the 0OP. The eight students who did not attend the OOP were studying a sport-related degree program that was similar to the physical education-related degree program studied by those who did attend the OOP. The semi-structured interview is an appropriate method of eliciting experience (Smith, Flowers, \& Larkin, 2009). Interviews were conducted within a month of the OOP.

The intervention group participated in all aspects of the OOP and results for the SACQ and semi-structured interviews are compared with a comparison group of similar characteristics. To maintain validity and rigor within the study, as reasonably could be controlled, all students received equal pastoral and academic support outside of the OOP residential provided by the university. The intervention group comprised students studying physical education and sport-related degree programs, justified on the basis that outdoor activities already form part of their degree program. The comparison group were studying a sport-related degree program; they were considered to have similar characteristics to the intervention group at the same university, but with no outdoor activity curriculum. All students from both groups were part of the same academic year group. Full ethical approval was gained from the host institution. 


\section{Results}

We first present the statistical findings of the student adaptation to university questionnaire; this is followed by analysis of the semistructured interviews. There was no baseline test carried out because the questionnaire is designed as a post-intervention measure as stipulated in the questionnaire handbook. It can't be known whether the intervention group was not already at a higher starting point of adjustment to university than the comparison group. However, explanations from a qualitative perspective between groups were used to increase confidence in the findings. Similarities between the intervention and comparison students in terms of entry requirements and demographics also further justify this post-intervention approach. Normality testing indicated that for each construct, and the full score, the data were normally distributed ( $p>0.05$ ) except the experimental condition for the construct of attachment. Therefore, an independent t-test was conducted for each construct except attachment. For the construct of attachment, the nonparametric equivalent of the independent $t$ test was used, which is the Mann Whitney U test.

\section{Results of Adaptation to University Questionnaire}

The intervention group scored higher $(+61.19)$ on the overall full score of adaptation to university $(\mathrm{M}=457.23, \mathrm{SD}=58.38)$ than the comparison group who did not attend the program $(M=396.04, \mathrm{SD}=69.19)$. An independent t-test showed that the difference between the experimental condition who attended the program and the comparison condition who did not attend the program was significant for the full score, $t(76)=4.07$, $p$ $<0.05,95 \%$ CL $[31.23,91.14]$. 


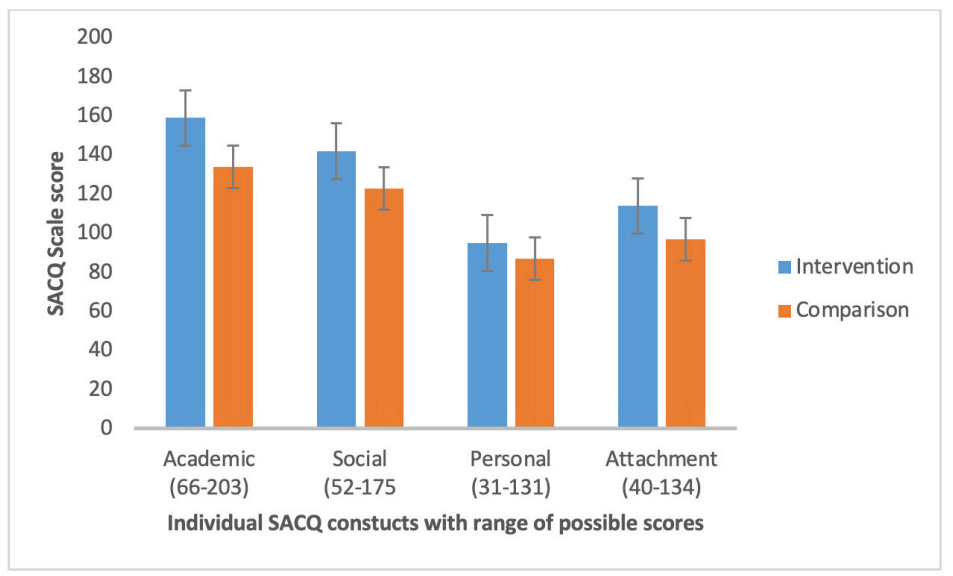

Figure 1. Constructs of the SACQ

Figure 1 shows the four individual constructs recorded by the SACQ. In each of the four constructs the intervention condition on average scored higher than the comparison group. In academic adjustment $(+25.08)$, in social adjustment $(+19)$, in personal adjustment $(+8.17)$ and finally in the institutional attachment construct the intervention condition again scored higher $(+16.92)$ than the comparison condition. A Mann Whitney $\mathrm{U}$ test indicated for the construct of attachment that there is a statistically significant difference $(\mathrm{p}<0.05)$ between the intervention condition who attended the residential and the comparison condition who did not attend the program. The findings of this questionnaire demonstrated that the students who attended the outdoor program adapted to university better on average than students studying a similar course who did not attend the outdoor program. The next stage of the analysis will attempt to discover in-depth why this occurred using a series of qualitative methods. Links between these constructs will be illuminated and explained through the data and previous research.

\section{Student Interview Analysis}

Table 1 presents the demographic profiles of interview participants including both OOP participants and those students in the comparison group who did not attend the 0OP. 


\section{Table 1}

Demographic Profiles of Interview Participants

\section{Name Age Campus/Commute OOP participant}

\begin{tabular}{|llll|}
\hline Emma & 20 & Commute & Yes \\
\hline Luke & 20 & Campus & Yes \\
\hline Alison & 21 & Campus & Yes \\
\hline
\end{tabular}

\begin{tabular}{|llll|}
\hline Michael & 20 & Campus & Yes \\
\hline Jack & 21 & Campus & Yes \\
\hline
\end{tabular}

\begin{tabular}{|llll|}
\hline Lucas & 22 & Campus & Yes \\
\hline Claire & 20 & Campus & Yes \\
\hline
\end{tabular}

\begin{tabular}{|llll|}
\hline Steve & 24 & Campus & Yes \\
\hline Carrie & 19 & Commute & Yes \\
\hline Tony & 20 & Campus & Yes \\
\hline
\end{tabular}

\begin{tabular}{|llll|}
\hline Tony & 20 & Campus & Yes \\
\hline Rose & 20 & Campus & Yes \\
\hline Bobby & 19 & Campus & Yes \\
\hline
\end{tabular}

\begin{tabular}{|llll|}
\hline Alex & 19 & Campus & Yes \\
\hline Rach & 20 & Campus & Yes \\
\hline Gemma & 20 & Campus & No \\
\hline
\end{tabular}

\begin{tabular}{|llll|}
\hline Gemma & 20 & Campus & No \\
\hline Gina & 19 & Commute & No \\
\hline Olivia & 19 & Campus & No \\
\hline Holly & 20 & Commute & No \\
\hline Ross & 21 & Commute & No \\
\hline Henry & 23 & Campus & No \\
\hline Josh & 19 & Campus & No \\
\hline Tom & 19 & Campus & No \\
\hline
\end{tabular}

This paper focusses on one part of a large research project. Table 2 illustrates one of the thematic areas (Social Development) found through qualitative methods relating to the focus of this paper, as well as the key related sub-themes, including that of Accelerated Friendships. 


\section{Table 2}

\section{Social Development Themes Generated From Outdoor \\ Orientation Program Research}

\begin{tabular}{|l|l|l|l|l|l|}
\hline Themes & \multicolumn{3}{|c|}{ Sub-Themes } \\
\hline $\begin{array}{l}\text { Social } \\
\text { Development }\end{array}$ & $\begin{array}{l}\text { Accelerated } \\
\text { friendships }\end{array}$ & $\begin{array}{l}\text { Initial } \\
\text { friendships }\end{array}$ & $\begin{array}{l}\text { Mixed } \\
\text { groups and } \\
\text { rooms }\end{array}$ & $\begin{array}{l}\text { Drinks in } \\
\text { the bar }\end{array}$ & $\begin{array}{l}\text { Technology } \\
\text { facilitating } \\
\text { friendships }\end{array}$ \\
\cline { 2 - 7 } & $\begin{array}{l}\text { Enhanced } \\
\text { friendships }\end{array}$ & $\begin{array}{l}\text { Extra } \\
\text { friendships }\end{array}$ & $\begin{array}{l}\text { Personal and } \\
\text { professional } \\
\text { relationships }\end{array}$ & $\begin{array}{l}\text { Platform } \\
\text { to work } \\
\text { together }\end{array}$ & $\begin{array}{l}\text { Friends } \\
\text { through } \\
\text { activities }\end{array}$ \\
\hline
\end{tabular}

\section{Accelerated Friendships}

The key theme Social Development had Accelerated Friendships emerge as the dominant factor through this residential experience. The term Accelerated Friendships is used as the dominant label for the outcome of this sub-theme, highlighted in the following analysis. The sub-themes support and provide a rich description of this key central idea, and it is through these sub-themes that this concept was recognized. Accelerated in this sense is used to articulate the speed with which social integration and other social processes were occurring between students, and the term friendship is used to describe meaningful connections made between young adults. Without this intervention, many of the young adults may have eventually come together naturally through their time at university. However, what the residential provided was a platform for these social networks to develop more widely and more quickly than in a regular university environment. Much is made of the social benefits, yet research has not clearly highlighted that it is the speed in which these social group formations occur which is a particular benefit of 00Ps. Getting these social support systems in place early is imperative in the process of transition and adaptation to university. This is made clear in the quote below.

I hadn't done a residential since like year 6 so I was looking forward to it in a sense that it's something new because I haven't done it in so 
long but then of course you are still thinking like you're going away with like 120 of us, new faces that you have probably never spoken to before or you haven't known them for that long so its throwing you in a situation where you might feel out of your depth but with the activities they have put on I felt that it really helped you socially in terms of getting to know people. (Michael)

The following sections of this thematic area will look to demonstrate how the 0OP accelerated the development and enhancement of social support networks.

\section{Mixed Groups and Rooms}

The allocation of roommates and activity groups was one of the most positively received elements of the OOP experience. This was one of the key factors in delivering the accelerated social support network formation.

Being put into a room with people I haven't met before was good because you're literally stuck and you have to get to know them. People who are quiet, there was always someone in the room to get them talking which is always a good thing. There was two quiet lads in our room me and this other lad. Me and this other lad got everyone talking and everyone had a good time after that. You just give them a question and listen to them, literally tell them you are listening to them. Most of the time people are too scared to be noticed. So show them some attention and they come out of their shells. (Toby)

The quote from Toby raises a number of interesting points. Firstly, it highlights that young adults are trying to overcome being socially "scared," and, secondly, it highlights the platform this sleeping arrangement provided for integrating young adults. The way in which the social integration in this setting was achieved was by limiting room size to allow for greater intimacy between young adults who were sharing a room in close physical proximity. This quality time in a closed space again accelerates friendship development.

It was a really good way to do it because if you put people in their friendship groups that's kind of limiting who they are going to talk to whereas put them in a group with new people who they haven't 
spoken to before, it doesn't force them but it gives them an easier setting to get to know people better because you are practically living with them for 3 days so you are going to get to know them aren't you. (Michael)

Michael states that students were "living" together. This provided a period of exposure to some of their course mates that is unique to the residential experience, this exposure and level of physical proximity encourages accelerated friendship. The following quote shows the value placed on connections made quickly based on spending time together during the residential, when these connections may have otherwise not developed at all.

One boy who I didn't really speak to got put in a room with me and now we speak near enough every day now and he lives in all saints as well, so I talk to him, sometimes he comes out with us so it was good that way so it helped with social aspects. (Jack)

The process illuminated in the quote below by Lucas is the general consensus from the student interviews regarding the allocation of rooms and activity groups and how it can help overcome initial fears of university life including the social judgement of others.

It was good really, I think if someone gave me the choice I probably wouldn't have picked the people I stayed with, I would've probably picked people I know, who live in my accommodation, I got put with people I didn't know existed, because we stayed together for a few nights and obviously we communicated, we became friends and took each other's Facebook and number and I think that helped. It was a bit intimidating at first when you walk into a room and there's 4 other lads you don't know, you think I hope they like me and don't think I'm embarrassing or make a fool of myself but yeah I thought that was a good way of doing it. (Lucas)

Despite the general positive feeling surrounding this, the strategy of allocating a group and roommates was not universally embraced.

To be fair I had Tony and that was a pretty painful experience I had George in who I still haven't spoken to since I got back. (Alex) Alex's quote raises an interesting point; the 00P experience provides 
a platform and environment for social integration, yet not all people are socially compatible.

\section{The Cascade Effect of Friendship Making}

The following quotes provide an insight into how relationships developed quickly through the shared time during the 00P. The daytime activities encouraged introductions and meetings while the social time in the bar served to cement these new relationships.

The drinking social, that's when everyone "came out of their shells," they stopped being like hi my name's Susan and started showing who they are, games came out and people started playing different drinking games and got smashed, it's always fun. In the morning you'd be able to go back to that person and be like, "yeah you did this last night" so everyone got a lot further into who everyone was... (Toby)

Toby's quote provides an indication of the deepening of relationships from strangers to acquaintances to friends that can be explained through social penetration theory (Altman \& Taylor, 1973). The quote also evidences how the cascade effect of friendship making increases the range of people they got to meet in a relatively short period of time. The cycle of forming and reforming of groups meant that multiple introductions to new people became commonplace. This expanded social networks and brought others together. This is exemplified in the quote below from Luke.

I went to the bar with the lads from my room and introduced them to the lad from my halls and he introduced me to his room some of the lads in my room introduced me to people from their flat at uni so we had a few drinks together, there was about 15 of us. (Luke)

\section{Developing Friendships Through Activities}

Gorge scrambling involved teamwork, cooperation and a high level of challenge and danger. This danger element required the young adults to trust one another in order to succeed. The quote below by Lucas also demonstrates that the OOP activities placed variable demands upon young adults based on their physical and social capabilities. 
The dangerous aspect of it you kind of rely on other people actually to help you. When you climb up rocks you rely not just on the instructor but your fellow students to help you get through it. On team building you communicate and talk to one another but if you have those skills already like communication skills you don't really improve but when you add that dangerous element where if you fall you could hurt yourself you have to rely on them more than yourself whereas in team building you don't have to rely on them. So I would say the gorge walking with the dangerous element was more beneficial to communication skills to help you pull through things so yeah that was more helpful than other activities. (Lucas)

The raft building activity required high levels of teamwork, imagination, and physical abilities to complete the build and successfully apply it while on the water.

Raft building, which was so fun. We worked really well together as a group and our raft was great, that was the one I was panicky about because of the swimming because I thought if I go in the water I don't really know what I'm going to do and I'll panic quite a lot but thankfully our raft because we worked that well together our raft was built really really well so even when other people got off it I still managed to stay on it so that one was really really fun. (Carrie)

The quotes of Lucas and Carrie about raft building and gorge scrambling highlight that these activities encouraged teamwork, cooperation, physical closeness, trust, shared goals, and shared fun experiences. The activities may therefore have had an effect on the accelerated development of social bonds through the transferable skills that are required to successfully complete the respective tasks.

\section{Enhancing and Expanding of Friendships}

The shared experiences and bringing people together also allowed acquaintances to develop into friendships, as demonstrated in the quotes below by Claire and Luke.

There is one boy from my floor and one from downstairs and the two were friends so we became friends with them as well, we got a lot 
closer on the trip so it was really good to know a lot of people before going. (Claire)

We've been out quite a bit together, I went into the city with one of the lads shopping yesterday to spend a bit of my birthday money, in class time we always work together and sit around together so yeah its gone well ever since. (Luke)

The program context and delivery style are targeted at providing a platform for these social interactions to occur though this unique residential time.

Not everyone considers the people they met on the residential to be their closest friends but the following quote highlights that through the OOP they now have additional contacts at university and a familiarity with many more people on their course.

I didn't spend that much with my friends we spent it with people we were staying with, this is going to sound stupid but I fed the ducks, other people started coming over, I didn't even know who they were, because you're stuck in one area and you can't go out and do things you make your own fun and because other people join on I spoke to people I didn't even know who existed, that helped because when you're in your class the people I had fun with are in my class as well so I can sit with and chat, I just helps like that really. So I didn't really spend a lot of my time with my friends who I live with or even people on my course, I spent time with people I didn't know. Because there was so many people in one area you had no choice really, that was better because it made your push yourself and talk to people and make friends with people you didn't know. (Lucas)

The quote from Lucas also makes another point about the targeted program context and delivery in that it demands a level of social effort from the participating young adults. The social platform provided could therefore be considered successful in encouraging fast development of social networks among young adults.

\section{Personal and Professional Relationships}

The residential quickly developed working relationships between the 
young adults who attended. These lasting connections could help students to support each other academically though sharing problems and offering each other support and guidance. The level of connection identified by Lucas below has led to a creativity-enhancing relationship.

Some people I shared a room with on residential I actually work in a group with back here on a module task for PE presentation, I did it with someone I roomed with on residential, because we already had a connection it felt easier and more confident in talking to him to work together and produce ideas so it did benefit me from that point of view. (Lucas)

This type of intervention may also be a good way for academic staff to be introduced and interact with young adults on a more social or "adult" level, which may be a different experience to previous relationships with academic staff. This could serve to break down barriers and improve interaction, as illustrated below.

The staff that we did get to meet were a good laugh really, they made us feel comfortable. It was good and in the free time especially they treat you like adults, they had a good sense of humour and you could say things that you wouldn't necessarily say at school or college to your tutors back then. It was a good laugh really. (Luke)

\section{Different Early Experience - Students Who Did Not Attend the OOP}

For students who did not attend the OOP, interview responses demonstrated a different outcome. The quote below is in stark contrast to the feelings of students interviewed who attended the residential. Fern has had limited opportunity to get to know her course mates, and the people she speaks to are best described as acquaintances. There has been no platform or opportunity to meet classmates on a more personal basis. Most of her friends are from halls but these are not on her course so wouldn't be able to directly support each other in academic work.

Who do you sit with in lectures? - I have one good mate on my course who is in my tutor group so probably him, I've met a few others, but I don't really talk to them that much on my course, I've only really made one good friend, the rest are in my flat. If we have group work 
to do I have people I can talk to pretty well but not that I would hang out with outside of uni

Is there any reason for that? - We haven't really bonded a lot, the only time we see each other is in class so you can't really just chat and get to know each other. (Fern)

Many of the students who attended the residential indicated that the trip was where they made their friends or grew their friendship groups. The same question was asked of how non-residential attending students made friends. Henry speaks about how he made friends through sports, but again these are not course mates. He also speaks about how he did not attend as many fresher's events as he thought he should. Henry also mentions the price of fresher's activities. Conversely, the residential was free for students.

A touch rugby tournament on the Friday, me and my mates took part in that, it was good fun actually, you then got in with the second and third years and started to socialise with them a bit more, I thought there would be a lot more segregation between first second and third years but that proved that they were quite friendly and you realised that they weren't as scary as they could have been. I didn't do an awful lot...I wish I would have done a little bit more in fresher's (Henry)

The quotes below from Gemma and Ross show that although halls can be a great place to meet people, this is not always the case. The residential provided an opportunity for all students attending the program to mix with all of their course mates. This large number of people to get to know must increase the chances of finding someone you can get along with and develop closer bonds.

I don't really get on with my flatmates that well, they are big drinkers and I don't drink so it's been hard they are not really the type of people I would choose to be friends with but you can't choose who you live with in the first year. (Gemma)

Within my flat there isn't a lot of communication... there are 4 people on my floor out of a possible 8 rooms. Two of them I never see and then one girl is on my course, so I speak to her. But other than that, I 
don't really socialise with that lot. (Ross)

The residential cut down the time it takes to make friends by putting people in situations which accelerate friendship such as group work, physical touch, overnighting together in rooms, and a shared goal.

The quote below illustrates the sometimes clumsy nature of making friends if the right platform is not provided:

When you have a lecture or seminar is there a set group of people you sit with? - Yeah I usually sit with the same people, I met them in fresher's week, I went to the fresher's fair but I hadn't really met any people that I'd gelled with yet so I went on my own and started having a walk around, I saw these three girls and I thought they looked really friendly so I asked them if I could tag along with them, they are the people that I hang around with. (Gemma)

Fresher's traditionally alcohol-based activities are not for everyone, as demonstrated in the quote below from Holly. Many students would like an environment where they can meet people but not feel they have to drink alcohol. The residential provided this type of opportunity. Even when activities took place in the bar, there was a quiz and other entertainment available, making a more inclusive environment.

Was fresher's a good introduction to uni for you? - Erm not really because I found a lot of events involved alcohol and the ones that weren't alcohol related not a lot of people turned up to so it made it quite difficult getting out there and meeting people and that kind of thing, I've never really being interested in it, being a gymnast my coaches were quite strict, I followed a strict training program, I didn't really have time to be going out. (Holly)

For the students who did not attend the residential some thought the university could have provided a better platform to meet people and integrate with fellow course mates. This is exemplified in the quote below from Gemma.

So, has it been a good start to university? - Partly and partly not, I'm not really sure how they would go about it but, I just feel like I could've met more people in that first week if there had been more opportunity to do stuff. (Gemma) 


\section{Student Conclusions of Attending the OOP}

A number of young adults made concluding statements about their residential experience and how it has affected them socially at university. These are powerful and they demonstrate some elements of the overall value of the residential experience. The quotes also highlight what is integral to the students and their university life - it is the friends and connections the students have made. It also demonstrates that the residential has played a key role in helping form and develop those friendships.

It's [0OP] helped me adapt because I'm mainly staying with people next year in a house through my course so that helped as well through that so it helps you adapt through who you are friends with, who you live with next year yeah so that's helped me. (Jack) For people coming up next year it [0OP] definitely helps in the beginning, then you can cement friendships through that as well. (Lucas)

\section{Discussion}

Firstly, the SACQ provided statistical evidence that the young adults who attended the OOP were better adapted to university than the comparison group. This paper explores the social construct of adaptation and transition to university and provides an explanation of why this difference was found. The framing and explanation of the key thematic research findings through psychological theory was also one of the aims of the research process. This was approached in a bottomup inductive approach which was data led. This was chosen to aid in the trustworthiness of the analysis process by reducing the risk of trying to fit parts of the analysis to a particular theory or psychological mechanism.

The theories which provide the best explanation of the accelerated friendship theme and sub-themes are attachment theory (Bowlby, 1969) combined with social penetration theory (Altman \& Taylor, 1973). The uncertain period of social upheaval being experienced by first-year students can pose challenges such as being separated from home ties and feelings of loneliness. This links to two of the measures proposed by 
Bowlby (1969), which are stranger anxiety and separation anxiety. The student is experiencing the loss of proximity to key social support from home friends and family. The young adults interviewed expressed how they were faced with a whole host of new strangers such as their peers and university staff. To overcome these attachment issues young adults must form new social support networks. Therefore, it is recommended that early delivery of this type of activity is essential to aid transition and adaptation for first-year students at university. This was evidenced throughout the sub-themes, with young adults transforming these strangers into meaningful connections and new attachments.

The 00P experience provided a platform for young adults to form attachments. Attachment theory posits that some individuals in this time of social upheaval may be less likely to seek out social relationships (Carr et al., 2013). The indications from the student interviews were that the OOP placed everyone in the same activity and social situations. This inclusive and collaborative shared environment could help firstyear university students by encouraging the development of these social interactions for people who otherwise may avoid such situations. Providing relational security during university transition may offset these heightened attachment concerns that certain young adults are prone to experiencing (McDonald \& Gunn, 1997). This is especially important in these early transitional stages of becoming a university student. The mechanism of friendship formation is also explained by Altman and Taylor (1973) in social penetration theory as detailed earlier in this paper. In this situation, the 0OP helped students to move through the four stages to develop stable relationships more quickly. The thematic findings have shown that for some students the environment and activities of the OOP encouraged accelerated friendships based on the shared living space, goals, and interests. Completing common challenges in a physical sense facilitates interactions, as does the shared goal of making friends. Peer support, as well as support from activity staff and university staff, helped in both social and personal terms. The close proximity in accommodation and the multitude of social spaces offered an opportunity to engage in the Exploratory Affective relationship stage. The activities also required physical 
contact which would not be normally expected until the Affective stage.

Creating an environment where young adults have access to support networks appears to be an integral factor influencing student adaptation (Tinto, 2006). This may be explained through the support these friendships can provide in academic adjustment at university. These relationships can provide help with practical sessions, group work, and a general feeling of ease with their fellow course mates. This further adds to research illustrating the benefit of using 00Ps to help first-year students to adapt and transition more quickly into university.

\section{OOP Blueprint}

This action research project has discovered a number of key elements required for a successful 00P. These elements were altered over the course of the research to create the best 00P experience for first-year students transitioning to university, as listed below:

\section{The OOP}

1. A critical component is that the OOP should be a residential experience with a minimum of two nights and three days. The element of rooming with peers overnight is essential to the 00P, because it provides a chance for all students, but especially nontraditional students such as commuting and mature students, to spend intimate time with fellow students. This environment helps accelerate friendships.

2. The location should be close to an area where outdoor experiential activities can take place, i.e. national parks, with a body of water and areas of outstanding natural beauty.

3. The quality of the accommodation is important for students, with a certain standard of rooms, social areas, and location. In addition, the food provided should be of a good standard.

4. An experienced company should be used to manage the OOP process and deliver the activities. Designing activities and timetables in collaboration can deliver the optimum experience while meeting budgetary commitments. Experienced team leaders 
can deliver great activities and educational opportunities for students as well as providing all equipment and transport to activity locations.

\section{Groups}

5. Preparation is key for the smooth running of any trip with a large number of participants. Accommodation groups and activity groups should be defined prior to setting off to reduce waiting time on arrival and allow activities to go ahead promptly.

6. Team leaders should be assigned to groups to help manage head counts and more importantly encourage everyone in the group to be an active member.

7. Groups should be between 7-15 students, as the optimum number to allow all group members to actively engage in activities and form friendships.

8. Groups should have an academic staff member or university representative in each group to allow students to get to know staff in an informal setting and break down perceived barriers. This is also thought to enhance belonging to the university.

\section{Activities}

9. In each day of the 00P there should be at least one memorable activity. This activity should be challenging, be something rarely experienced, and involve the natural environment. This type of activity can help build resilience and bring people together through shared experience.

10. One of the activities should take in the local environment/village/ town to allow students to explore the area, adding to providing a fun experience.

11. Having an academic module with relevance to the OOP reinforces the idea that it is a university trip and encourages students to reflect on their experiences.

12. Free time activities are also an essential element of the OOP. The informal timetable of activities during the evening helped develop friendships in an inclusive environment, for example a 
pub quiz or sports tournaments. These again place people in groups and help more reserved students join in when they otherwise may not.

\section{Limitations}

The findings were very positive about the 00P social experience for first-year university students. However, these findings were based at a small university. The direct application to other larger institutions with different student demographics could present different results. That having been said, the common feelings of being nervous and requiring a strong social support network are generally found throughout most incoming new students (Rubin \& Wright, 2015). This research also had a focus on explaining how an 00P influences social development through rich experiential data. Therefore, the data set size was fit for the purpose.

\section{Conclusion}

This OOP had a positive effect on first-year students' social adaptation to university. This was achieved through providing a platform which encourages social support network formation. The SACQ provided statistical evidence of the adaptation. The processes have been illustrated through illuminative quotes and analysis, and explained through attachment theory and social penetration theory. The cohort under investigation was studying a physical education-based degree, and as part of their course program there was an outdoor adventure activities module in the syllabus. This allowed the 00P to be integrated into their studies seamlessly. Future research could focus on other residential orientation programs for different student disciplines. 


\section{References}

Allan, J., McKenna, J., \& Robinson, M. (2008). Building student resilience through first-year Outdoor Adventure residential experience in higher education. Assessment, Learning and Teaching Journal, 4 (Summer), 6-9.

Altman, I., \& Taylor, D. A. (1973). Social penetration: The development of interpersonal relationships. Holt, Rinehart \& Winston.

Baker, R. W., \& Siryk, B. (1989). Student adaptation to college questionnaire: Manual. Western Psychological Services.

Bell, B. J. (2005). College students' development of social support and its relationship to preorientation experiences (Unpublished doctoral dissertation). University of New Hampshire, Durham.

Bell, B. J., \& Chang, H. (2017). Outdoor orientation programs: a critical review of program impacts on retention and graduation. Journal of Outdoor Recreation, Education, and Leadership 9 (1): unpaginated.

Bell, B. J., Gass, M.A., Nafziger, C.S. and Starbuck, J.D. (2014). The State of Knowledge of Outdoor Orientation Programs: Current Practices, Research, and Theory. Journal of Experiential Education. 37 (1): 31-45.

Bell, B. J., Holmes, M. R., \& Williams, B. G. (2010). A census of outdoor orientation programs at four-year colleges in the United States. Journal of Experiential Education, 33, 118.

Bhaskar, R. (1975). A realist theory of science. York: Books.

Bowlby, J (1969/1982). Attachment and loss: Vol. 1. Attachment. New York: Basic Books.

Braun, V., \& Clarke, V. (2006). Using thematic analysis in psychology. Qualitative research in psychology, 3 (2), 77-101.

Carr, S., Colthurst, K., Coyle, M., \& Elliott, D. (2013). Attachment dimensions as predictors of mental health and psychosocial well-being in the transition to university. European journal of psychology of education, 28(2), 157-172.

Cortez, K. J. (2014). "Outcomes assessment of an outdoor orientation program through means-end theory." Masters Theses. 718.

Credé, M., \& Niehorster, S. (2012). Adjustment to college as measured by the student adaptation to college questionnaire: A quantitative review 
of its structure and relationships with correlates and consequences. Educational Psychology Review, 24(1), 133-165.

Ewert, A. W. (1983). Outdoor adventure and self-concept: A research analysis. Institute of Recreation Research \& Service, Department of Leisure Studies \& Services.

Grayson, J. P., \& Grayson, K. (2003). Research on Retention and Attrition.

Montreal: Canada Millennium scholarship Foundation

HESA. (2019a.). Higher Education Student Data. Retrieved from http:// www.hesa.ac.uk.

HESA. (2019b, March 7). Non-continuation: UK Performance Indicators 2017/18. Retrieved from http://www.hesa.ac.uk.

Hill, E., Posey, T., Gómez, E. and Shapiro, S.L. (2018). Student Readiness: Examining the Impact of a University Outdoor Orientation Program. Journal of Outdoor Recreation, Education and Leadership. 10 (2): 109-123.

Lincoln, Y. S., \& Guba, E. G. (1985). Establishing trustworthiness. Naturalistic inquiry, 289, 331.

Mattern, K. D., \& Patterson, B. F. (2009). Is Performance on the SAT® Related to College Retention? Research Report No. 2009-7. College Board.

Maxwell, J. A., Spielmann, S. S., Joel, S., \& MacDonald, G. (2013). Attachment theory as a framework for understanding responses to social exclusion. Social and Personality Psychology Compass, 7(7), 444-456.

McKenzie, M. D. (2000). How are adventure education program outcomes achieved?: A review of the literature. Australian Journal of Outdoor Education, 5 (1), 19

Peel, M. (2000). Nobody cares': The challenge of isolation in school to university transition. Journal of Institutional Research, 9 (1), 22-34.

Pickard, L. (2019). How does an outdoor orientation programme aid transition and adaptation to university for 1st year students. Thesis for PhD. DOI: 10.13140/RG.2.2.13415.60321

Richmond, D., \& Sibthorp, J. (2019). Bridging the Opportunity Gap: College Access Programs and Outdoor Adventure Education. Journal of Outdoor Recreation, Education, and Leadership, 11 (4): 301-319. 
Rubin, M., \& Wright, C. L. (2015). Age differences explain social class differences in students' friendship at university: Implications for transition and retention. Higher Education, 70(3), 427-439.

Schofield, C., \& Dismore, H. (2010). Predictors of retention and achievement of higher education students within a further education context. Journal of Further and Higher Education, 34(2), 207-221.

Shannon-Baker, P. (2015). Making paradigms meaningful in mixed methods research. Journal of Mixed Methods Research, 1, 16.

Shenton, A. K. (2004). Strategies for ensuring trustworthiness in qualitative research projects. Education for information, 22(2), 63-75.

Sibthorp, J., Paisley, K., \& Gookin, J. (2007). Exploring participant development through adventure-based programming: A model from the National Outdoor Leadership School. Leisure Sciences, 29 (1), 1-18

Smith, J. A., Flowers, P., \& Larkin, M. (2009). Interpretative Phenomenological Analysis: Theory. Method and Research London: Sage.

Thomas, L. (2012). What works? Student retention \& success. York, UK: Higher Education Academy.

Tinto, V. (2006). Research and practice of student retention: What's next? Journal of College Student Retention, 8, 1-19.

Vlamis, E., Bell, B. J., \& Gass, M. (2011). Effects of a college adventure orientation program on student development behaviors. Journal of Experiential Education, 34(2), 127-148.

Wolfe, B. D. and Kay, G. (2011). Perceived Impact of an Outdoor Orientation Program for First-Year University Students. Journal of Experiential Education, 34 (1): 19-34. 